\title{
Oficina Expressiva em Centro de Atenção Psicossocial: Relato de Experiência de Estágio
}

\author{
Expressive Office in Psychosocial Attention Center: Internship Experience Report
}

Oficina Expressiva en Centro de Atención Psicosocial: Relato de Experiencia de Etapa

\author{
Amanda Borba Ramos Silva \\ Stephannie Assenheimer \\ Ana Laura Pires Rodovalho \\ Taís Xavier Rigobello \\ Rafael Camilo Gonçalves \\ Renata Fabiana Pegoraro ${ }^{1}$ \\ Universidade Federal de Uberlândia
}

\begin{abstract}
Resumo
O objetivo deste artigo é apresentar o relato de experiência da implementação de uma oficina expressiva em dois centros de atenção psicossocial a partir de um estágio profissionalizante em Psicologia. As oficinas integram atualmente o rol das atividades realizadas pelos Centros de Atenção Psicossocial e podem ser classificadas como expressivas, de geração de renda e de leitura. Para a composição deste artigo, foram analisados os registros efetuados por quatro estagiários de Psicologia, sob a forma de diário de campo, ao longo de um semestre de estágio desenvolvido no ano de 2015. Cada dupla de estagiários coordenou uma oficina de argila em um Centro de Atenção Psicossocial. O espaço livre da oficina permitiu a construção de vínculo entre estagiários e usuários, o resgate de histórias de vida e a valorização da singularidade do usuário, além de contribuir para a formação profissional.
\end{abstract}

Palavras-chave: oficinas expressivas, atenção psicossocial, reforma psiquiátrica

\begin{abstract}
The objective of this article is to present the experience report of the implementation of an expressive workshop in two centers of psychosocial care from a professional internship in Psychology. The workshops are currently part of the activities carried out by the Psychosocial Care Centers1 and can be classified as expressive, generating income and of reading1. For the composition of this article, the records of four trainees of Psychology, in the form of a field diary, were analyzed during a semester of a traineeship developed in the year 2015. Each pair of trainees coordinated a clay workshop in a Center of Psychosocial Attention.. The free space of the workshop allowed the construction of a link between trainees and users, the rescue of life histories and the appreciation of the singularity of the user, besides contributing to the professional formation.
\end{abstract}

Keywords: expressive workshops, psychosocial attention, psychiatric reform

\section{Resumen}

El objetivo de este artículo es presentar el relato de experiencia de la implementación de un taller expresivo en dos centros de atención psicosocial a partir de una etapa profesional en Psicología. Los talleres integran actualmente el rol de las actividades realizadas por los Centros de Atención Psicosocial1 y pueden ser clasificadas como expresivas, de generación de renta y de lectura1. Para la composición de este artículo, se analizaron los registros efectuados por cuatro pasantes de Psicología, en forma de diario de campo, a lo largo de un semestre de etapa desarrollado en el año 2015. Cada pareja de pasantes coordinó un taller de arcilla en un Centro de Atención Psicosocial. El espacio libre del taller permitió la construcción de vínculo entre pasantes y usuarios, el rescate de historias de vida y la valorización de la singularidad del usuario, además de contribuir a la formación profesional.

Palabras clave: talleres expresivos, atención psicosocial, reforma psiquiátrica

\footnotetext{
${ }^{1}$ Endereço de contato: Universidade Federal de Uberlândia, Campus Umuarama, Instituto de Psicologia, Av. Pará, 1720 - Bloco 2C, Sala 47, Bairro Umuarama, Uberlândia, MG, CEP 38405-320. E-mail: rfpegoraro@yahoo.com.br
} 


\section{Introdução}

O objetivo deste artigo é apresentar o relato de experiência da implementação de uma oficina expressiva em dois Centros de Atenção Psicossocial (CAPS) a partir de um estágio profissionalizante em Psicologia. As oficinas são práticas de cuidado a grupos frequentemente desenvolvidas em serviços de saúde mental no Brasil. Atualmente, as oficinas integram o rol das atividades realizadas pelos Centros de Atenção Psicossocial (Brasil, 2004) e podem ser classificadas como expressivas, de geração de renda e de leitura. Outras classificações definem este tipo de intervenção grupal como espaços de criação, de atividades manuais ou de promoção de interação (Delgado, Leal, \& Venâncio, 1997). Para além dessa perspectiva mais atual, a presença das oficinas enquanto atividades expressivas ou vinculadas à prática laborativa é registrada desde longa data no Brasil e em experiências internacionais. Um breve resgate histórico sobre a implementação de oficinas voltadas às pessoas em sofrimento psíquico se faz, portanto, necessário.

Na Europa, a partir do fim do século XVIII e início do século XIX, mudanças na forma de se compreender a loucura e o contexto socioeconômico a partir do qual surgiam sociedades industriais levaram para os asilos uma tentativa de terapêutica por meio do trabalho. Acreditava-se que este poderia reabilitar os sujeitos, além de restaurar ou manter a ordem social (Ribeiro, Sala, \& Oliveira, 2008). Essa premissa era fundamentada no ideário alienista e no tratamento moral, sendo assim, na internação o doente estaria privado do cotidiano da vida urbana, considerado principal causador das perturbações mentais naquela época. No Brasil, no fim do século XIX, os primeiros asilos criados no país adotaram o modelo de intervenção proposto acima. Uma variação desta prática foram as colônias agrícolas para tratamento psiquiátrico, associadas à vida fora da cidade, nas áreas rurais, vistas como potenciais promotoras de benefícios ao doente em decorrência do clima no campo e pelo propósito de que o exercício do trabalho assumisse um papel terapêutico. As intervenções calcadas no trabalho envolviam os mais variados tipos: desde cultivar a terra até trabalhos com couro e madeira.

Surgiram no Brasil, já na primeira metade do século XX, diferentes configurações das colônias existentes na Europa, como os asilos-colônias ou até mesmo as colônias para pacientes com problemas específicos, tais como epiléticos, tuberculosos e leprosos. Já em 1895, ainda no século XIX, quando construído, o Hospício do Juqueri obedecia a esse modelo e às diretrizes propostas no Congresso Internacional de Alienistas, em 1889, recomendando a existência de colônias agrícolas (Venâncio, 2011). Multiplicaram-se, durante o século XX no Brasil, as práticas de ergoterapia ou laborterapia (Lima, 2004) e o modelo agrícola foi tomando outras formas, adotando uma configuração de "hospital colônia". Exemplo desse modelo é a Colônia Juliano Moreira, fundada na área rural de Jacarepaguá, no Rio de Janeiro, que tinha real propósito de sanar os problemas que foram surgindo nas antigas colônias de alienados da Ilha do Governador (Venâncio, 2011).

Todavia, tal qual ocorrera na Europa, as novas concepções biológicas para a explicação da loucura ganharam terreno e colocaram as práticas relacionadas ao trabalho relegadas a ocupação do tempo dentro do hospício, assumindo uma de suas funções iniciais de modo mais explícito: uma forma de controle dos internos. As primeiras intervenções medicamentosas e cirúrgicas, tais como a lobotomia, o eletrochoque e a insulinoterapia, foram introduzidas 
no Brasil e passaram a ser cada vez mais frequentes na assistência psiquiátrica do país. Na contramão desse modelo asilar e de uma psiquiatria biológica, surgiram no Brasil pioneiros capazes de implementar uma intervenção terapêutica diferente ao modelo proposto nos asilos, tais como Osório Cesar, no Hospital Psiquiátrico do Juquery na década de 1920 e Nise da Silveira, no Centro Psiquiátrico Nacional, no Rio de Janeiros dos anos 1940. Osório Cesar passou a observar os trabalhos artísticos dos internos do Juquery e a analisá-los, comparando os traços aos de grandes artistas. Ele também promoveu essa atividade no Hospital e, em seguida, expôs as obras em um museu. Como pano de fundo dessa prática e da criação de uma escola de artistas dentro do hospital, Osório César intencionava a identificação de artistas e a possibilidade de que essa fosse uma profissão ou ocupação para o interno quando reinserido na comunidade. Já Nise da Silveira, imprimiu uma terapêutica ocupacional em um largo sentido, mas o principal objetivo era que essas atividades envolvendo pintura, desenho e escultura servissem aos internos como uma ferramenta de expressão (Lima, 2004). Nise, com base na Psicologia Analítica de Jung, buscava compreender a produção de cada interno como movimento das forças inconscientes, ou seja, como manifestação da psyché.

Segundo Mendonça (2005), o uso da atividade artística coloca o foco no processo de construção e criação do novo utilizando a produção dos acontecimentos, ações, objetos e experiências, reinventando o mundo. Ainda que no Brasil o termo "oficina" seja muito utilizado no cotidiano dos serviços de atenção psicossocial, outras denominações se fazem presentes internacionalmente. As denominações utilizadas para essas propostas de intervenção refletiam os sentidos dados às mesmas. Na Itália, os laboratórios tinham a ideia de experimentação e pesquisa, nos quais se pensavam novas possibilidades de universos simbólicos, de trocas, de sociabilidade, de vida. Na experiência francesa La Borde, os ateliês assumiam a ideia de criação artística, a qual permitia ou possibilitava a criação de territórios existenciais. No Brasil, a partir da Reforma Psiquiátrica, surgem as oficinas que trazem a ideia de produção de subjetividade, sendo espaços que de criação de novas formas de experimentar, relacionar e existir (Lima, 2004). Portanto, ateliês, laboratórios e oficinas colocam em cena a ideia de espaço para propostas de atividades expressivas e artísticas, bem como de experimentação, de possibilidade de criação livre (Mendonça, 2005), propiciando a construção da história do sujeito, de suas linguagens e seus significados (Lima, 2004).

Ribeiro et al. (2008) apoiam essa perspectiva no sentido de que, além de considerarem as oficinas como elementos organizadores do cotidiano dos serviços de saúde mental, compreendem tais práticas como espaços de produção e manejo da subjetividade, que propiciam a reconstrução dos vínculos do sujeito e seus grupos sociais. Esses autores destacam também que as oficinas terapêuticas constituem novas formas de acolhimento, de diálogo, de convivência e acompanhamento. Para Mendonça (2005) as oficinas em saúde mental se configuram também como instrumento que enriquece os sujeitos, valorizam a sua expressão, descobrem e ampliam as possibilidades do sujeito ser.

Nos últimos 20 anos surgiram e ainda vem surgindo inúmeras práticas de atividades expressivas, produtivas e criativas que fizeram com que se pensasse de melhor forma o uso desses recursos para o cuidado à pessoa em situação de sofrimento psíquico. As experiências inovadoras de Osório César e Nise da Silveira, ambas na primeira metade do século XX, são agora retomadas como exemplos de formas de cuidado alinhadas aos ideais da Reforma Psiquiátrica Brasileira (Lima, 2004). 


\section{Oficina e Arte: Recursos Expressivos em Atividade Realizada Durante Estágio Profissionalizante em Psicologia}

As discussões sobre o lugar do louco e da loucura na sociedade, a exploração de novos aspectos e possibilidades de cuidado em instituições de saúde mental e a criação de serviços extra-hospitalares a partir da década de 1990 no Brasil descortinaram novos modos de cuidar (Lima, 2004). Segundo o Ministério da Saúde (Brasil, 2004), nos Centros de Atenção Psicossocial, as oficinas são atividades frequentemente disponíveis para os usuários. As oficinas podem assumir um modelo expressivo, utilizando-se de materiais que propiciem a expressão verbal, corporal, musical e plástica, por exemplo. Outra possibilidade são as oficinas geradoras de renda, onde, por meio do aprendizado de atividades, que podem ser de culinária, costura, fotografia, marcenaria, ou artesanatos em geral, há uma tentativa de inserção do sujeito nos espaços da cidade por meio da circulação dos produtos elaborados no espaço da oficina. As oficinas são realizadas em grupo, com a coordenação de um ou mais profissionais do serviço, definidas a partir dos interesses e necessidades dos usuários, das possibilidades dos técnicos, buscando a integração social, manifestação de sentimentos, desenvolvimento de habilidades e o exercício coletivo da cidadania (Brasil, 2004).

As oficinas caminham no sentido de possibilitar ao sujeito estabelecer e fortalecer laços de cuidado consigo, com o trabalho e com os outros, apresentando finalidade clínica (Mendonça, 2005). Ribeiro et al. (2008) destacam também que as oficinas se caracterizam como atividades grupais que se destinam à socialização familiar e comunitária dos usuários, à expressão de emoções e sentimentos, ao desenvolvimento de suas potencialidades e autonomia, e ao exercício da cidadania.

Muitas oficinas atualmente são desenvolvidas por meio de recursos artísticos. Baumgart (2007) afirma que desde a pré-história a atividade artística servia à interpretação do mundo e do homem no mundo, tendo proporcionado menos a realização prática da vida do que à sua organização. Como princípio ordenador, representa um dos meios mais diretos de dominar o caos exterior e interior do homem, de modo que o desconcertante, assustador e inconcebível da vida só pode ser ordenado ao receber forma. A arte é a configuração do desordenado, que sempre significa ameaça. Na pesquisa feita por de Morais, Roecker, Salvagioni, e Eler (2014), observou-se que as técnicas artísticas possibilitaram aos participantes a vivência de suas dificuldades, conflitos, medos e angústias de um modo menos sofrido. Além disso, atividades artísticas foram um eficaz meio para canalizar, de maneira positiva, as variáveis do sofrimento psíquico, assim como os conflitos pessoais e com familiares. Notou-se que há uma minimização dos fatores negativos de ordem afetiva e emocional, tais como: angústia, medo, agressividade, isolamento social, apatia, entre outros.

Nas oficinas, dentre os vários materiais possíveis para mediar a expressão de vivências e sentimentos, a argila pode ser um facilitador de descarga de emoções (Morais, Roecker, Salvagioni, \& Eler, 2014), possibilitando que a pessoa tenha prazer pelo ato em si, e também a sensação de controle de seus sentimentos, através de suas mãos. Para os autores, é possível, com o uso desse material, a comunicação de conteúdos conscientes ou inconscientes, expressando sentimentos e sensações, em razão de a atividade com uso de argila poder proporcionar liberação de tensão, prazer e relaxamento pelos movimentos e contato das mãos na moldagem de peças/imagens. 
A partir dessas afirmações teóricas, e considerando o contexto de realização de um estágio profissionalizante em Psicologia desenvolvido em Centros de Atenção Psicossocial, foi proposta a duas equipes de diferentes CAPS a realização de oficinas de argila, com o intuito de promover o contato dos participantes com conteúdos do seu psiquismo através do uso livre do material. Nessas oficinas, a atividade propiciaria um espaço de criação e expressão que poderia ser utilizado pelo usuário com liberdade, respeitando seu tempo e formas de simbolização, bem como o desejo ou não de uso da palavra/expressão verbal ao longo da atividade, o que possibilitaria agregar usuários que nem sempre participavam das rodas de conversa que ocorriam nos CAPS nos horários do estágio.

O estágio foi desenvolvido em Centros de Atenção Psicossocial em funcionamento em um município do Estado de Minas Gerais e encontrava-se vinculado à ênfase de Psicologia Clínica e Social, sendo realizado por alunos dos últimos três semestres letivos do curso. Os estagiários eram organizados em duplas para a prática nos CAPS, com carga horária de dez horas semanais na instituição, divididas em três dias da semana. Ao longo da semana, os estagiários desempenhavam, juntamente aos profissionais dos CAPS, atividades como acoIhimento, visita domiciliar, oficinas, reuniões de família, grupos terapêuticos, reuniões de equipe e discussões de caso. Além das atividades práticas realizadas no CAPS, os alunos participavam de quatro horas de supervisão semanal com a professora orientadora, faziam leituras previamente indicadas, efetuavam o registro das atividades em um diário de campo (relatório diário de estágio no qual devem ser registradas ações, pensamentos e sentimentos do estagiário frente à prática) e elaboraram um relatório final de estágio.

A inserção dos alunos no campo de estágio ocorreu a partir da observação das atividades já desenvolvidas em cada CAPS. Nas duas semanas iniciais do estágio as atividades solicitadas aos alunos consistiam na observação das práticas usuais nos serviços. Essa etapa de observação foi importante para que o aluno pudesse conhecer a rotina do serviço, o perfil dos usuários, o modo de trabalho da equipe e pudesse refletir de que modo era afetado por tudo isso, registrando no seu diário de campo produzido a cada ida ao CAPS e levando tais registros para as discussões em supervisão. Após essa etapa, começaram a ser delineadas as práticas grupais a serem desenvolvidas pelos estagiários ao longo do semestre. Neste momento, foi possível confirmar junto às coordenações dos CAPS que, conforme observado pelos estagiários nos dois serviços, alguns usuários pouco ou nada participavam de atividades grupais desenvolvidas pela equipe. A esses usuários as equipes denominavam "circulantes", ou seja, usuários que frequentavam o CAPS, mas no geral não aderiam a grupos e oficinas. A partir disso, foi elaborada a proposta de oficina expressiva com argila, com leitura de textos e discussão em supervisão, a qual foi estruturada para discussão com as equipes.

A proposta da oficina foi elaborada com base em Afonso (2015)' sendo destacados o objetivo da oficina, o público-alvo, local para realização das atividades, materiais necessários, data, horário e forma de convite aos usuários. Foram desenvolvidas uma oficina em cada CAPS, nas tardes de segundas-feiras, durante o primeiro semestre de 2015, com duração média de 90 minutos cada. Antes do início da oficina, os estagiários convidavam usuários que não haviam se integrado às atividades grupais oferecidas pelos CAPS naquele momento, organizavam espaço físico e materiais e permaneciam disponíveis para iniciar a atividade, tão logo os usuários se aproximassem. O fluxo nesta oficina era livre, ou seja, era permitido 
entrar, sair, voltar, permanecer fazendo argila, ficar conversando com outros usuários ou com os estagiários, pintar peças, de forma que a liberdade para estar ali pudesse ser enfatizada, e a permanência pudesse ser estabelecida a partir da atividade ou do vínculo em construção com os estagiários.

\section{Aspectos Metodológicos}

Para a composição deste artigo, foram analisados os registros efetuados por quatro estagiários de Psicologia, sob a forma de diário de campo, ao longo de um semestre de estágio desenvolvido no ano de 2015, em que cada dupla de estagiários coordenou uma oficina de argila em um Centro de Atenção Psicossocial. Segundo Minayo (2002), o diário de campo é um local para notas (um pequeno caderno ou um arquivo eletrônico) em que são registradas informações não gravadas durante entrevistas na fase de campo de uma pesquisa. Tal qual Bogdan e Bilken (1994) compreendemos que as notas de campo precisam, inicialmente, ter um caráter descritivo, que permita "captar uma imagem por palavras do local, pessoas, acções [sic] e conversas observadas [e um outro, mais profundo e reflexivo, que permita, na sua leitura apreender] o ponto de vista do observador, as suas ideias e preocupações" (p. 152).

No caso do presente artigo, o diário de campo fazia parte da estratégia de ensino-aprendizagem do estágio, pois a cada ida à instituição, cada estagiário deveria compor um diário daquele dia, entregando-o impresso na supervisão imediatamente posterior, de forma a permitir a discussão das intervenções realizadas. O diário de campo utilizado no estágio servia, ainda, para o registro de pensamentos e sentimentos suscitados pela prática. Após o encerramento do estágio, todos os diários produzidos no semestre letivo foram impressos e lidos integralmente por um estagiário diferente daquele que efetuou o registro. Em seguida, foram separados os trechos que se referiam às oficinas com argila em um arquivo de editor de texto, e o material, agora selecionado, foi novamente impresso e lido para o agrupamento dos sentidos que emergiam dos registros. Neste momento, os estagiários formaram duplas para releitura desses registros e os mesmos foram discutidos na presença de todos os autores, isto é, incluindo-se um quinto estagiário que participou de todas as supervisões, mas foi responsável por outras atividades no serviço, e a supervisora. Na sequência, houve reorganização dos temas, em função de sua exclusividade em apenas uma categoria e elaboração das categorias temáticas de análise (Bardin, 1977) em sua versão final, tal qual se descreve aqui. Na próxima seção, os diários 1 e 2 referem-se aos estagiários alocados no CAPS 1 e os diários 3 e 4 referem-se aos estagiários do CAPS2.

\section{Reflexões sobre a Prática a Partir dos Registros em Diário de Campo}

A atividade inicial de preparo dos estagiários consistiu em discutir literatura sobre atividades grupais e, em seguida, realizar uma vivência para manuseio da argila. O material do qual dispúnhamos, naquele momento, era em forma de grânulos, conseguidos em uma olaria local por iniciativa de uma das estagiárias. Na parte externa do bloco de aulas da universidade, no espaço gramado, nos reunimos para preparar a massa da argila e perceber de que modo seu toque afetava cada um de nós. Essa atividade permitiu que alunos, de forma lúdica, com ou sem experiência no uso de materiais artísticos trocassem impressões e, aqueles com pou- 
ca ou nenhuma experiência, se sentissem mais à vontade para dar início às atividades com os usuários nos CAPS.

Os relatos dos primeiros encontros grupais registram que as experiências iniciais com a argila provocaram certa estranheza, em alguns usuários, pelo toque no material. Áspera, pouco acolhedora. A argila é resistente. O contato direto com a argila foi recusado em alguns casos, como apontam os diários: "K. chega na oficina e fica conosco, mas sem mexer na argila. Não gosta de sujar a mão" (Diário 3) ou ainda "O usuário S. também chegou a participar, fez uma bola e acho que não gostou quando pegou uma argila muito molhada e sujou a mão. Falou sobre a sensação e foi limpar sua mão" (Diário 4).

Neste sentido, de Morais et al. (2014) discorrem sobre o que o material pode despertar em cada usuário. O contato pode ser gratificante ou não com o material, pode provocar rejeições, retomada de situações delicadas anteriormente vividas, e ainda trazer à tona sentimentos de alívio ou desprazer. O contato com o material de uma oficina pode, ainda segundo os autores, despertar emoções que, quando vêm à superfície, poderiam resgatar memórias um tanto esquecidas pelo sujeito, como destacado a seguir:

$X$, um usuário que ficava a maior parte do tempo deitado fumando, conseguiu participar da oficina de argila e fez várias peças, sempre saindo e voltando, chegando ele mesmo fazer a [massa de] argila no ponto que queria sem precisar de minha ajuda. Achei interessante ele fazer várias peças e ir nomeando todas elas, que mesmo sem terem muito acabamento, lembravam os objetos pela forma, por exemplo, fez uns peixes pequenos e como eles o lembravam de férias que passou na praia. (Diário 4)

O uso da argila como material primário permitiu a emergência de afetações e mobilizações que antes eram desconhecidas dentro da história de cada usuário no serviço, fossem estes conteúdos conectados ou não a obra que estava em produção. O caráter de acolhimento e escuta da atividade permitiu que existisse um espaço de diálogo na instituição para que o usuário compartilhasse suas angustias e aflições através de histórias pessoais, como conflitos familiares e sociais. Enquanto produzia a obra "Confuso", o usuário Y. relat à estagiaria que assim registou em seu diário:

Me conta que sua mãe saiu de casa e o deixou com o pai, mas que um dia ela voltou para levar ele e o irmão em um passeio ao circo, pontua que ela sempre falava para as outras pessoas que eles não eram seus filhos e que desta vez no circo fez a mesma coisa, falando que ele era filho da macaca e, diz ele, ela o deixou lá e Y. ficou um tempo no circo. Y. ainda me contou outra história sobre sua infância, disse que construiu uma pequena casa de madeira que dava para entrar dentro e que lá era o ambiente mais seguro, ele descreve como era a casa e os objetos que tinha colocado lá, como uma lamparina de querosene. (Diário 3)

Nas oficinas de argila percebeu-se que o vínculo era de suma importância para o desenvolvimento de trocas que construíssem novas formas de ressignificação sobre a atividade exercida na instituição e os sofrimentos psíquicos da vida dos usuários. As trocas entre as pessoas (usuário-usuário e usuário-coordenador-usuário) e a atividade (o barro, as peças, e a pintura) ocorriam de forma singular, ou seja, as razões e aproximações de cada usuário se davam através de afetações diferentes, fosse com um dos estagiários que coordenava, com 
a própria instituição, com o processo artístico, consigo mesmo ou com outros usuários.

Não apenas memórias afetivas do passado puderam ser pronunciadas. Questões raciais e socioeconômicas surgiram por meio da representação da argila, sendo o material associado às palavras "preto", "pobre" e, mais uma vez, "sujeira", como observado no diário: "Neste momento me recordo das falas de S. em outros dias, que descrevia a sujeira da argila, e relacionava a cor preta ao emprego [de faxineira] de sua mãe" (Diário 3).

O trabalho de faxineira, exercido pela mãe deste usuário, reflete sobre a sua própria condição social. Muitas vezes é exercido pela mulher, negra, pobre, sem escolaridade e que vive sob condições precárias, o que fortalece ainda mais o estigma loucura-pobreza e o preconceito acerca disso, acarretando efeitos não apenas no sujeito, mas também no núcleo familiar. A esse respeito, vale dialogar com Ludermir e Melo Filho (2002). Esses autores relacionaram escolaridade formal menor do que quatro anos, condições precárias de moradia e baixa renda familiar per capita com maior frequência de transtornos mentais comuns do que aqueles que tinham melhores condições de vida. Estes autores também destacam que outros estudos apresentam que no Brasil as desigualdades sociais afetam negativamente a saúde mental da população. Para além da literatura, destaca-se aqui que grande parte dos usuários do serviço são de origem pobre e suas famílias desempenham trabalhos de menor prestígio social. Em outro estudo, Wiemann e Munhoz (2015) apontam prevalência de transtornos mentais comuns em situações de vulnerabilidade social vividas pela população de baixa renda, afirmando o impacto das desigualdades sociais sobre essas populações que se encontram, por muitas vezes, em situação de miséria, sofrimento e violência física e psicológica.

\section{Oficina como Espaço para Construção de Vínculos}

Aos poucos, foi possível perceber que o espaço construído na oficina foi um facilitador para o estreitamento do vínculo estagiários-usuários. A oficina constituiu-se como local para novos meios de expressão, principalmente com usuários que não aderiam a outras atividades propostas pelo CAPS, chamados pelas equipes de "circulantes" e também por aqueles entendidos como "em crise". Eram esses os usuários que participaram da proposta. Exemplo disso eram diálogos iniciados durante a oficina e que tinham continuidade após seu término.

Conversamos por pouco mais de uma hora. Ele me contou sobre as formas que o sofrimento o machuca e pude apreender um pouco da estrutura do seu delírio. Pelo que compreendi, ele crê que existe um líder superior (não é Deus), sendo seu servo, mas ele mesmo possui servos, de modo que é difícil lidar com a responsabilidade que o líder delega, porque nem sempre dá para cumprir [o que Ihe foi delegado] e pelo fato de que ele ama seus servos e não quer vê-los sofrer, quer ajuda-los, pois é essa a sua razão de ter nascido: ajudar os outros. Ele trouxe sobre a liberdade. Conta que ama o seu líder porque ele foi benevolente o suficiente para dar isto para ele, conversamos também sobre o amor, não apenas nas relações, mas em sua forma mais subjetiva, em como ele abrange a todos. (Diário 3)

Essa construção, que ocorre aos poucos, e permite descortinar sentimentos e delírios, vai apontando para os estagiários que o CAPS é um local para cuidar, que a clínica é ampliada, que o acolhimento não se restringe ao primeiro atendimento do usuário, e que o respeito 
pelas histórias e pelos sofrimentos devem ser o carro-chefe dos profissionais que atuam na rede de atenção psicossocial. Esse contato mais próximo permite que os quadros diagnósticos, discutidos pelas equipes e nos livros de Psicopatologia, fiquem mais distantes da forma de pensar o cuidado, que deve ser dirigido às necessidades de uma pessoa que se encontra em situação de sofrimento psíquico, e não de uma pessoa dotada de um diagnóstico psiquiátrico. Neste sentido, concordamos com Serpa Junior, Leal, Louzada, Silva Filho e Corley (2007) sobre a necessidade de, em atividades de ensino, auxiliarmos o aluno a desenvolver um olhar que critique:

[...] uma clínica onde (1) a ideia de adoecimento mental desconsidera o modo do sujeito operar no mundo; (2) a avaliação psicopatológica se restringe à indicação de presença ou não de sintomas; (3) privilegia como indicador do adoecimento mental apenas a observação da presença/ausência de alterações tipo delírios e alucinações (p. 219).

Deste modo, a oficina também afetou a formação dos alunos. Permitiu que usuários "que nunca aderem" passassem a participar, a esperar a oficina, além de serem percebidos pela equipe de outro modo, pois passaram a se interessar pela atividade, a falar sobre si, a resgatarem trechos de suas vidas que a equipe, mesmo com algum tempo de tratamento, não conhecia. As histórias pessoais que emergiram ao longo da oficina possibilitaram que os estagiários percebessem o que já haviam lido: que o CAPS, enquanto um serviço com finalidades terapêuticas, tem como meta maior o cuidado para com o usuário em sua singularidade, logo, deve ser um espaço para a construção de vínculos que permitam a expressão e (re) construção da subjetividade. Ao longo do semestre, foi possível, pela leitura dos diários, discutir o papel de cuidado do profissional de saúde, independente de sua formação. O cuidar não deve ser visto como um procedimento ou uma intervenção, mas como uma relação que busca a melhoria da qualidade de vida do indivíduo, respeitando e compreendendo suas vivências. $\mathrm{O}$ ato de cuidar não se limita aos sinais e sintomas clínicos da doença, mas atua nas modificações que ocorrem na estrutura dos seres humanos e abalam sua totalidade. Neste serviço, o cuidar envolve sentimentos, preocupações com a higiene, alimentação, interação e escuta terapêutica (Coelho \& Jorge, 2009). Por meio do cuidado singular, constrói-se o vínculo.

A palavra vínculo, em sua origem etimológica, "significa algo que ata ou liga pessoas", que "indica interdependência, relações com linhas de duplo sentido, compromissos dos profissionais com os pacientes e vice-versa" (Campos, 2003 citado por Jorge et al., 2011, p. 3053). Com a construção de vínculo, puderam ser expressas algumas ideias dos usuários sobre os estagiários e a equipe. Algumas destas ideias permitem problematizar o serviço oferecido naquele CAPS do ponto de vista dos usuários que participaram da oficina de argila:

Constataram estar cansados das atividades do CAPS e disseram que quando a gente [estagiárias] estivesse formadas, "com jaleco", a gente 'não faria mais a oficina de argila'. Quando eu pergunto o motivo, eles dizem: 'vocês vão ficar só lá dentro, chamando para conversar', mostrando como eles questionam o posicionamento das profissionais e das oficinas que são propostas. (Diário 2)

Aqui, como em outros momentos do estágio, evidenciou-se uma "queixa" dos usuários com relação à equipe, que se envolvia menos do que eles desejavam nas atividades 
oferecidas no serviço. Enquanto um ou dois técnicos estavam nas atividades grupais com a maior parte dos usuários, outros estavam em atendimentos individuais, acolhimento, busca ativa por telefone. Para se aproximar desta lógica de cuidado, é preciso que o usuário seja ouvido, pois é ele quem usufrui do serviço e pode indicar o que tem sido satisfatório e o que o que tem ficado de fora do tratamento, em outras palavras, que o usuário também seja sujeito atuante do seu tratamento. Percebemos que o caráter livre da nossa oficina abriu novos espaços nos serviços, possibilitando que usuários falassem o que acham sobre o CAPS, culminando em avaliações dos usuários sobre seus próprios tratamentos e sobre o funcionamento do serviço.

A opção por estar com os estagiários também ocorreu por ser, para alguns, uma opção à rotina da unidade, como exemplifica o trecho abaixo que descreve a reação de algumas usuárias quando convidadas para a oficina de argila: Elas fizeram uma cara de desespero! Começaram a falar que iriam para [oficina de] argila, pois não aguentavam mais "essas conversas" [propostas nas rodas de conversa]. (Diário 3). A "alternativa" oferecida pelos estagiários também foi comentada ao longo da oficina:

Nos contam que não gostam dos momentos de conversa no CAPS porque são todos as mesmas coisas, como disse E: 'Faço tratamento há 5 anos no CAPS. Há 5 anos vejo tal profissional fazer a mesma coisa'. Comentam que se sentem julgadas, pois "você conta sua história e 'todo mundo bica'. (Diário 3)

Desta forma, coloca-se em pauta a forma como tem sido exercida a tarefa dos profissionais no serviço, que se volta para um atendimento individual e clinico, limitando o reconhecimento e apropriação dos espaços comuns para cada sujeito, e, consequentemente, também limitando as trocas entre os sujeitos as quais cooperam para mobilizações e rupturas de seu sofrimento. Nos ajuda refletir a perspectiva de Silva (2009), apoiada em Winnicott, em que o autor destaca que:

Um indivíduo só se constitui pela presença de alguém que reconheça e, portanto, humanize sua existência. Para que esse encontro aconteça, tem que haver um entorno constituído principalmente pela confiabilidade e continuidade dessa relação . . . Assim, podemos questionar até que ponto é possível, dentro de uma instituição, propiciar ao indivíduo com intenso sofrimento psíquico um espaço suficientemente bom para que ele possa, através dessa relação, descongelar situações de fracasso e adquirir uma abordagem mais criativa da vida. (p. 292)

Fica nítida assim a importância de um vínculo que seja para além dos momentos individuais entre profissional e usuário. É desejável que o vínculo também se estabeleça entre os próprios usuários em situações que possam suscitar rupturas através do convívio em grupo, sendo as oficinas um espaço propicio para o mesmo. Nas palavras de Anzie (citado por Moretto \& Terzis, 2010), o grupo é um espaço que permite acolher os participantes, mas também provocar-Ihes "sentimentos de aprisionamento e frustração" (Anzie, 1966/1990 citado por Moretto \& Terzis, 2010, p. 43). Pádua e Morais (2010) pontuam que as atividades grupais realizadas nas oficinas expressivas:

[...] são intermediárias na construção de vínculos entre participante-oficineiro e participante-participante. Elas podem fazer que a palavra circule e que o usuário compartilhe 
suas histórias, experiências e sentimentos que, até aquele momento, não tiveram a possibilidade de ser expressos, escutados e acolhidos. (p. 465)

É através da relação do vínculo que podemos perceber ao longo do tempo as formas que cada usuário constrói o seu discurso subjetivo, o que dá margem para espaços de intervenção e aproximação através de uma escuta ativa. O estudo de Souza, Kantorski, e Mielke (2006) registrou uma repetição de atividades oferecidas por profissionais de CAPS da região sul do Brasil e uma impossibilidade de perceber novas formas de atuar. Isso repercute no serviço, em suas formas de intervenção e na eficácia na reabilitação dos usuários. Em nosso caso, a fala do usuário que está no CAPS há cinco anos e vê o mesmo sendo feito desde que ingressou revela também o tempo de permanência dos usuários neste serviço, teoricamente transitório, e toda a problemática envolta nesta questão. O estudo de Pande e Amarante (2011) revela que os CAPS surgiram com a proposta de superar o modelo asilar, mas podem retomar a institucionalização e criar novas formas de cronificação de usuários. Usuários que desafiam os limites entre o que já é estabelecido pelo serviço e pelos profissionais tem suas reivindicações vistas como produto de sua doença mental; familiares e usuários acreditam que precisarão ser atendidos até o fim de suas vidas pelo CAPS e não são informados sobre a possibilidade de encaminhamento para outros serviços; técnicos, buscando um cuidado efetivo dos usuários, se respaldam na impossibilidade de cura do transtorno mental e apenas variam a frequência de suas rotinas quando apresentam melhoras, tendo um baixo índice de altas no serviço.

Como a presença dos estagiários no CAPS era para além dos horários da oficina, momentos voltados para acolhimento e aproximação também se estendiam, o que, somado ao caráter livre da atividade com argila (fazer o que quisesse, sair e voltar se desejasse, falar ou não) possibilitou a abertura de diferentes formas de expressão. A adesão de alguns "circulantes" foi notada pela coordenação dos serviços e pontuada em reunião com a supervisora. Percebe-se então uma nova forma de estar na instituição por parte dessas pessoas, posto que se sentiram à vontade para explorar as possibilidades do ambiente:

Um dos usuários começou a falar muito sobre argila, contando que faz [um curso de artes e tem estudado] sobre argila. Começou a nos explicar sobre algumas técnicas. Falamos para ele fazer uma obra também, ele sentou e fez um rosto tridimensional. No momento de ir limpar as coisas encontrei com ele no tanque e ele ficou me mostrando fotos dos quadros e das esculturas que ele já fez. (Diário 2)

Desta forma, é através da relação horizontal construída entre profissional e usuário, onde não há um que saiba mais, e sim alguém interessado pelo outro, em sua história, que pode emergir uma ligação que permita confiança, cuidado e corresponsabilização, o que permite que o usuário se abra para intervenções:

Enquanto conversamos fui fazendo pontuações e perguntas no intuito de que ela descobrisse qual lugar ocupa em sua própria vida e quais os seus desejos, das diferenças e necessidade de respeito entre as pessoas, assim como movimentos em prol de um empoderamento dela. Quando ela traz suas dificuldades e a forma como vive isso, não vejo alguém desequilibrada [como ela se definira], mas sim o produto de uma sociedade opressora que sempre a direcionou para ser a mulher, dona de casa que vive para cuidar 
do marido e dos filhos, sendo que tal posição entra em conflito com seus sentimentos, vontades e valores. Só que ser assim é a única perspectiva que ela entende como possível em sua vida, devido às falas constantes de sua mãe e irmã sobre como ela "faz tudo errado". (Diário 3)

A possibilidade de construção da autonomia ocorre na medida em que ambos conseguem lidar com suas próprias redes de dependências, coprodução de si mesmo e do contexto. Nesse caso, baseando-se no texto de Campos (2007), Jorge et al. (2011) percebem que "a formação da atitude corresponsabilizada requisita o compromisso e o contrato mútuo, evitando dissonâncias cotidianas na possibilidade de se conviver e de se trabalhar em prol de algum propósito" (p. 3053).

Dell'Acqua e Mezzina (2005) discorrem que deve haver uma priorização da aproximação e (re)conhecimento do sujeito como um ponto de partida do seu tratamento, já que o momento em que se dá atenção à pessoas em crise pode ser identificado como o ponto de máxima simplificação de uma relação onde, por um lado, o sujeito que está por mostrar-se já fez, progressivamente, uma simplificação e expressou sintomaticamente a complexidade da sua existência de sofrimento; por outro lado, o serviço, qualquer que seja ele, equipou-se de modo especular para perceber e reconhecer - oferecendo-se como modelo de simplificação - o próprio sintoma.

É preciso, portanto, distanciar-se do que é sintoma e aproximar-se do sujeito ou da pessoa em situação de sofrimento psíquico grave através de uma prática que se fundamente no acoIhimento, no diálogo, no vínculo, na corresponsabilidade e na escuta ativa entre profissional e usuário dos serviços de saúde. Isto porque "a integralidade está presente no encontro, na conversa, na atitude do profissional que busca prudentemente reconhecer, para além das demandas explícitas, as necessidades dos cidadãos no concernente à sua saúde" (Gomes \& Pinheiro, 2005, p. 290).

Notamos, então, que a institucionalização pode ocorrer mesmo em serviços territoriais que visam a substituição do modelo hospitalocêntrico, se os profissionais não se apropriarem da nova forma de cuidado que estes serviços exigem. É apenas dando voz aos usuários que perceberemos como eles ainda são afetados por estas problemáticas e o que pode ser feito diferente. Com a disseminação dessa informação, profissionais e gestores terão consciência e embasamentos críticos para minimizar estes problemas, gerando mudanças necessárias para a real transformação no modelo de atenção à saúde mental (Pande \& Amarante, 2011).

\section{Considerações Finais}

Este relato de experiência discutiu a relevância de atividades grupais de caráter expressivo em contexto de serviço de atenção psicossocial, a partir da recuperação dos diários de campo elaborados pelos estagiários que conduziram as oficinas em CAPS. Inicialmente, portanto, este texto valoriza a formação do profissional de Psicologia por meio da inserção em estágio supervisionado. A possibilidade de identificar demandas de cuidado aos usuários, planejar uma ação, discutir sobre sua implementação com a equipe e conduzir a prática grupal contribui para a formação de profissionais de Psicologia com mais flexibilidade para o trabalho em equipe, que precisa ser discutido nos espaços reservados para as reuniões, de forma a representar uma proposta de cuidado construída coletivamente pelos profissionais e que atinja, de 
forma singular, aos usuários que a ela se vincularem. A possibilidade de um espaço menos estruturado permitiu a construção de vínculo com os estagiários, permitiu que esses se colocassem no papel de facilitadores e refletissem sobre a necessidade de ofertar diferentes ações de cuidado aos usuários vinculados ao serviço. Destaca-se, como limites do estudo, tratar-se de relato de experiência em apenas dois serviços ao longo de um semestre letivo. Sugere-se a problematização de outras experiências de estágio, de intervenções profissionais ou pesquisas com os usuários de serviços de saúde mental com dificuldades para construir vínculos com o serviço e também que possam opinar sobre as ações de cuidado realizadas nesses serviços, de forma a serem chamados para construir a atenção psicossocial mais ativamente.

\section{Referências}

Afonso, M. L. A. Como conduzir uma oficina. (2015). In M.L.M. Afonso (Org.), Oficinas em dinâmica de grupo na área da saúde (pp. 283-309). São Paulo: Pearson.

Bardin, L. (1977). Análise de conteúdo. Lisboa, Portugal: Edições 70.

Baumgart, F. (2007). Breve história da arte. São Paulo: Martins Fontes.

Bogdan, R., \& Biklen, S. (1994). Investigação qualitativa em educação. Porto, Portugal: Porto Editora.

Brasil. (2004). Ministério da Saúde. Secretaria de Atenção à Saúde. Departamento de Ações Programáticas Estratégicas. Saúde mental no SUS: Os centros de atenção psicossocial. Disponível em http://www.ccs.saude.gov.br/saude_mental/pdf/SM_Sus.pdf

Coelho, M. O., \& Jorge, M. S. B. (2009). Tecnologia das relações como dispositivo do atendimento humanizado na atenção básica à saúde na perspectiva do acesso, do acolhimento e do vínculo. Ciência \& Saúde Coletiva, 14(5), 1523-1531. Disponível em http://www.redalyc.org/html/630/63012430023

Delgado, P., Leal, E., \& Venâncio, A. (1997). O campo da atenção psicossocial. Anais do 10 Congresso de Saúde Mental do Rio de Janeiro.

Dell' Acqua, G., \& Mezzina, R. (2005). Resposta à crise: Estratégia e intencionalidade da intervenção no serviço psiquiátrico territorial. In P. Amarante (Ed.), Arquivos de saúde mental e atenção psicossocial (pp. 161-194). Rio de Janeiro: Nau.

Gomes, M. C. P. A., \& Pinheiro, R. (2005). Acolhimento e vínculo: Práticas de integralidade na gestão do cuidado em saúde em grandes centros urbanos. Interface - Comunicação, Saúde, Educação, 9(17), 287-301. doi https://dx.doi.org/10.1590/S1414-32832005000200006

Jorge, M. S. B., Pinto, D. M., Quinderé, P. H. D., Pinto, A. G. A., Sousa, F. S. P., \& Cavalcante, C. M. (2011). Promoção da saúde mental - Tecnologias do cuidado: Vínculo, acolhimento, co-responsabilização e autonomia. Ciência \& Saúde Coletiva, 16(7), 3051-3060. doi https://dx.doi.org/10.1590/S1413-81232011000800005

Lima, E. A. (2004). Oficinas, laboratórios, ateliês, grupos de atividades: Dispositivos para uma clínica atravessada pela criação. In C. M. Costa, \& A. C. Figueiredo (Eds.), Oficinas terapêuticas em saúde mental - Sujeito, produção e cidadania (pp. 59-81) (Coleções IPUB). Rio de Janeiro: Contra Capa Livraria.

Ludermir, A. B., \& Melo Filho, D. A. (2002). Condições de vida e estrutura ocupacional associadas a transtornos mentais comuns. Revista de Saúde Pública, 36(2), 213-221. doi https://dx.doi.org/10.1590/S0034-89102002000200014 
Mendonça, T. C. P. (2005). As oficinas na saúde mental: Relato de uma experiência na internação. Psicologia: Ciência e Profissão, 25(4), 626-635. doi https://dx.doi.org/10.1590/ S1414-98932005000400011

Minayo, M. C. S. (2002). Pesquisa social. Teoria, método e criatividade. Petrópolis, RJ: Vozes. Morais, A. H., Roecker, S., Salvagioni, D. A., \& Eler, G. J. (2014). Significado da arteterapia com argila para os pacientes psiquiátricos num hospital de dia. Investigación y Educación en Enfermería, 32(1), 128-138. Disponível em http://www.scielo.org.co/scielo. php?script=sci_arttext\&pid=S0120-53072014000100015\&lng=en\&tlng=pt

Moretto, C. C., \& Terzis, A. (2010). O sofrimento nas instituições e possibilidades de intervenção grupal. Arquivos Brasileiros de Psicologia, 62(3), 42-47. Disponível em http:// pepsic.bvsalud.org/scielo.php?script=sci_arttext\&pid=S1809-52672010000300006\&lng $=p t \& t \operatorname{lng}=p t$

Pádua, F. H. P., \& Morais, M. L. S. (2010). Oficinas expressivas: Uma inclusão de singularidades. Psicologia USP, 21(2), 457-478. doi: http://dx.doi.org/10.1590/ S0103-65642010000200012

Pande, M. N. R., \& Amarante, P. D. C. (2011). Desafios para os Centros de Atenção Psicossocial como serviços substitutivos: A nova cronicidade em questão. Ciência \& Saúde Coletiva, 16(4), 2067-2076. doi https://dx.doi.org/10.1590/S1413-81232011000400006

Ribeiro, L. A., Sala, A. L., \& Oliveira, A. G. (2008). As oficinas terapêuticas nos centros de atenção psicossocial. REME - Revista Mineira de Enfermagem, 12(4), 516-522. Disponível em http://www.reme.org.br/artigo/detalhes/296

Serpa Junior, O. D., Leal, E. M., Louzada, R. C. R., Silva Filho, J. F., \& Corley, G. (2007). Including subjectivity in the teaching of Psychopathology. Interface - Comunicação, Saúde, Educação, 3(se). Disponível em http://socialsciences.scielo.org/scielo. php?script=sci_arttext\&pid=S1414-32832007000100020\&lng=en\&tlng=en

Silva, M. C. F. (2009). O trabalho suficientemente bom na instituição. Anais do XVIII Congresso Latino-Americano FLAPAG e X Simpósio CEFAS: práticas institucionais na América Latina: casal, família, grupo e comunidade (p. 292), Campinas, SP.

Souza, J. D., Kantorski, L. P., \& Mielke, F. B. (2006). Vínculos e redes sociais de indivíduos dependentes de substâncias psicoativas sob tratamento em CAPS AD. SMAD. Revista Eletrônica Saúde Mental, Álcool e Drogas, 2(1), 0-0. Disponível em http://pepsic.bvsalud. org/scielo.php?script=sci_arttext\&pid=S1806-69762006000100003\&lng=pt\&tlng=pt

Venancio, A. T. A. (2011). Da colônia agrícola ao hospital-colônia: Configurações para a assistência psiquiátrica no Brasil na primeira metade do século XX. História, Ciências, Saúde-Manguinhos, 18(Suppl.1), 35-52. doi https://dx.doi.org/10.1590/ S0104-59702011000500003

Wiemann, I., \& Munhoz, T. N. (2015). Prevalência de transtornos mentais comuns e fatores associados nos usuários do Centro de Referência de Assistência Social de São Lourenço do Sul, RS. Ensaios e Ciências: Biológicas, Agrárias e da Saúde, 19(2), 89-94. Disponível em http://pgsskroton.com.br/seer/index.php/ensaioeciencia/article/view/3187/2925 
Recebido: 19/01/2018

última revisão: 22/02/2018

Aceite final: 07/03/2018

\section{Sobre os autores:}

Amanda Borba Ramos Silva - Graduada em Psicologia pela Universidade Federal de Uberlândia. E-mail: borba.manda@gmail.com

Stephannie Assenheimer-Graduada em Psicologia pela Universidade Federal de Uberlândia. E-mail: s.assenheimer.psico@gmail.com

Ana Laura Pires Rodovalho - Graduada em Psicologia pela Universidade Federal de Uberlândia. E-mail: analaurarodovalho@hotmail.com

Taís Xavier Rigobello - Graduada em Psicologia pela Universidade Federal de Uberlândia. E-mail: rigobellotais@gmail.com

Rafael Camilo Gonçalves - Mestrando no curso de Psicologia e Graduado em Psicologia pela Universidade Federal de Uberlândia. E-mail: rafael_camilo@hotmail.com

Renata Fabiana Pegoraro- Doutora e Mestre em Psicologia pela USP/Ribeirão Preto, SP. Especialista em Saúde Coletiva pela UFSCar. Psicóloga pela USP/Ribeirão Preto, SP. Professora Adjunta do Instituto de Psicologia da Universidade Federal de Uberlândia (UFU). E-mail: rfpegoraro@yahoo.com.br 
